\title{
MERGING FORMALITY AND INFORMALITY IN DISPUTE RESOLUTION
}

\author{
Yoshitaka Wada*
}

From a legal sociologist's perspective of focusing on the views of the participants themselves, this article considers the various positions adopted with respect to Alternative Dispute Resolution, identifies unexplored issues, and argues that a dynamic view of dispute resolution implies the need for considerable fusion of formal and informal aspects in almost all dispute resolution processes.

\section{INTRODUCTION: HIV SETTLEMENTS AND PERSPECTIVES ON DISPUTE RESOLUTION}

In Japan, disputes involving HIV infection have recently been settled through court conciliation procedures. During the disputes, medicine companies formally apologised in a press conference reading from a prepared statement. The victims severely criticised this attitude, saying that their apology was not sincere. They were also critical of the conciliation proposals put to them by the court which focused on monetary compensation. After further difficult negotiations, the court put forward revised proposals which included terms going beyond monetary compensation. Executives of the medicine companies accepted these proposals and met representatives of the victims in person, bowing down to them on the floor. In Japan, this is regarded as an expression of deepest remorse and of true apology. After this, the victims seemed to begin to accept the terms of the settlement, including monetary compensation. Eventually, they also accepted the revised proposals. ${ }^{1}$ In addition,

* Professor of Law, Kyushu University, Fukuoka, Japan. An earlier version of this article was presented at a lecture co-hosted by the New Zealand Institute of Dispute Resolution and Research, and the New Zealand Association for Comparative Law, at Victoria University Law Faculty on 12 June 1996. I thank participants, and also the New Zealand Asia 2000 Foundation for assistance during my stay in Wellington.

1 Including wakaikin or ichijikin (one-off settlement payments), kenkokanri teate (ongoing monthly payment), etc. For the terms of the settlement agreement, see T Awaji "HIV Sosho to Wakai [HIV Litigation and Settlement]" (1996) 1093 Juristo 52. 
the state had also been sued by the victims and had agreed as part of the settlement to negotiate with the victims about establishing an effective system of socio-medical research and treatment for HIV infection. The course of these negotiations will also be facilitated by the companies' public expression of remorse. In both cases, the formal content of the settlement agreement remained the same, but its meaning for all involved had changed. In other words, parties' perceptions of what constitutes true compensation will change as the "extra-legal" aspects of disputes are transformed during the course of disputes and their aftermath.

In this HIV case, the victims mobilised the power of the press and television, ${ }^{2}$ and were successful in making companies respond to and define the problem in the victims' own terms: of interpersonal relationships or consideration owed to them, rather than purely as a matter of money. On the other hand, this process is not necessarily the same in more frequent tort cases. This problem will be reconsidered in the context of traffic accident cases at the end of this article. First, however, dispute resolution needs to be discussed more generally.

Over the last few decades, all over the world, alternative dispute resolution (ADR) or extra-judicial dispute resolution has been institutionalized, aiming for more flexible procedures and for fast and simple dispute resolution. Many positions have been taken as to the proper role of ADR and, as a result of this debate, the meaning of litigation as a formal means of dispute resolution has also been reconsidered.

However, discussion of a number of important issues is noticeably lacking in the structure of the arguments about dispute resolution engendered by this ADR movement. "Informal dispute resolution versus formal dispute resolution": is this basic antinomy not itself problematic? Or, when the performance of dispute resolution institutions is evaluated, are there not problems with the implicit or explicit performance standards? Rethinking these sorts of questions leads us to a more detailed study of dispute resolution processes, whether "formal" or "informal".

From this perspective, this article first reviews the various arguments as to the relationship between formal and informal dispute resolution within the ADR movement. It points out a number of issues which have not been raised or extensively argued, aiming to take dispute resolution research to new levels. In particular, the issues are revisited from a legal sociological perspective, stressing the views of participants themselves. ${ }^{3}$

2 Cf the less visible process whereby New Zealanders infected with HIV from imported blood products settled their claims with the Australian government: "Kiwi HIV Victims in Secret Payment", The Dominion (21/12/96).

3 This article follows on, at more general level, from my earlier work including empirical research into landlord-tenant disputes (Y Wada Minji Funso Kosho Kateiron [The Theory of Civil Dispute Negotiation Processes] (Shinzansha, Tokyo, 1991), and subsequent general reformulation (Y Wada 


\section{PERSPECTIVES ON THE ADR MOVEMENT}

Normally, informal and formal dispute resolution are sharply contrasted. The progression of ADR worldwide is said to have been a reaction to the inability to cope effectively with small claims and relational disputes under a system where procedures have been rigidified as in normal litigation. However, arguments on ADR have developed along two axes: positive versus negative overall evaluations, and an emphasis on ADR's cooperative or competitive relationship with formal litigation processes. This section of the article therefore briefly reviews both pro-ADR and anti-ADR positions, further dividing the perspectives into those which favour formal litigation processes and those which are critical of them.

\section{A The Pro-ADR Pro-Litigation Position}

Probably the most common appraisals of ADR in both Japan and New Zealand belong in this category: the view that justice can be quantitatively improved by establishing the appropriate relationship between $\mathrm{ADR}$ and the structures and functions of pre-existing formal litigation processes, taking the basic raison d'être of the latter for granted. There are two major variants relating to the division of functions between ADR and litigation. Respectively, they stress:

(1) the efficiency and smooth functioning of litigation; and

(2) the expansion of access of justice.

\section{Efficiency of Litigation}

In this first variant, important objectives are improving performance and efficiency of the civil justice system, centred on litigation, by expanding ADR. To prevent disfunctionalities in litigation, such as delays, cases are to be divided into those which truly necessitate resolution by formal processes and those which can be adequately dealt with more simply, with only the former to be dealt with by litigation. Thus, ADR is expected both to deal with appropriate cases under more simple processes such as mediation and arbitration, and to exercise a screening function transferring more difficult cases to more formal processes. In this way, the formal judicial system is to better fulfil the functions originally expected of it.

Minji Funso Soriron [The Theory of Civil Dispute Resolution] (Shinzansha, Tokyo, 1994) esp 127161). See also, S Tanaka Gendai shakai to Saiban [Contemporary Society and Litigation] (Kobundo, Tokyo, 1996); and Susan Silbey and Austin Sarat "Dispute Processing in Law and Legal Scholarship: From Institutional Critique to the Reconstruction of the Judicial Subject" (1989) 66 Denv U L Rev 437. 
Numerous practical criticisms are raised against this variant: whether or not establishing more ADR will in fact reduce the burden on the civil justice system or contribute to better achievement of its functions, or whether rational channeling is really possible. More important for the purposes of this article is that the traditional ideals of the formal litigation process are taken for granted - their better achievement becomes the prime objective - and that the existence of cases more appropriate for formal processes and of those more appropriate for informal processes is also assumed a priori. These two assumptions will be discussed further below (at III).

Generally speaking, this variant is a narrower, more conservative reaction to the phenomenon of the ADR movement. A major, possibly primary focus is on reducing the burden on the formal judicial system. Typically, this sort of exercise is seen as "technical": improving productivity in processing cases through the system. Of course, a longer-term aim in so doing may be to increase overall access to the system - the "access to justice" variant discussed at (2) immediately below. Alternatively, however, the aim may simply be to make the performance of formal court procedure more efficient from the viewpoint of court administration.

An example of this more conservative, technical attitude is the recent effort by Japanese jurists to undertake a large-scale amendment of the Code of Civil Procedure (enacted in June 1996 and due to come into force in 1998). There was very little theoretical discussion of the possible interrelationship between amendment of the Code and ADR in general. By contrast, much energy was expended on how to improve productivity and case management within the formal litigation process. ${ }^{4}$

\section{Access to Justice}

Although sometimes linked to the first, the second variant in the Pro-ADR Pro-Litigation perspective focuses less on fulfilling formal litigation processes themselves. Rather, the aim is to guarantee access to justice for more classes of people who have not traditionally been able to access the civil justice system, and to improve the performance of the legal dispute resolution system as a whole for them. By replacing litigation with its high attendant costs in terms of time and money with cheap, fast informal systems, this variant specifically hopes to divert more disputes into the expanded legal arena and thus help legal dispute resolution become more prevalent in society. Invariably, dispute resolution by ADR is compared with model dispute resolution by formal litigation processes. Often, the latter is considered

4 There was comparatively little discussion on the role of ADR in discussing aspects of the amendment. Part 8 of the Code on arbitration has been left for separate reconsideration. Further, although there is a long tradition of court-annexed mediation (chotei) in Japan, this remains regulated not by the Code but by separate legislation. See also the special issues on the amendment to the Code in general, in (1996) 1098 Juristo and (1996) 68/11 Horitsu Jiho. 
superior. That is because the "resolution" presented by the most procedurally refined formal litigation process is taken as correct, and thus the presentation of a resolution basically similar to the latter is taken as the ideal. Of course, there are occasions when original and flexible resolution different to that presented by the litigation process is stressed. However, this does not become a general criticism of resolution through litigation. Rather, it is seen as a minor adjustment to particular circumstances.

This view has also found favour in Japan, although perhaps less so than in other jurisdictions, and it is less prevalent than the "efficiency" variant mentioned in (1) above. ${ }^{5}$ An example of this attitude can be found in the recent establishment of a variety of Product Liability Dispute Resolution Centers in Japan, which are considered indispensable in Japan where the number of lawyers is kept very low, making litigation an expensive and unpopular option. This view also accords, for instance, with the actualities of dispute resolution in Traffic Accident Disputes Resolution Centers, generally seen as the most successful example of ADR in Japan. ${ }^{6}$ However, this second variant also undoubtedly takes the traditional formal processes of litigation as the "core" of the entire dispute resolution system. Furthermore, we can note that the notion of access to justice really amounts to the advance of the legal system to the furthest reaches of social life - an aspect of "juridification" of social life, which opens itself in particular to direct criticism from the Anti-ADR Anti-Litigation view mentioned briefly in Part II.D below.

\section{B The Pro-ADR Anti-Litigation Position: Community Mediation}

Amidst the movement generally favouring ADR, there is a contrasting view which raises fundamental doubts about the existing formal processes in litigation. Beginning with the apprehension that those processes not only fail to resolve the problems rooted in social relationships between the disputing parties, but often even lead to further disintegration of those relationships, this view proposes original ADR quite independent of the legal system. As with the San Francisco Community Board, for instance, even procedural matters can be dealt with by trained (but non-lawyer) community members, following an ideal typified by

5 See generally T Kojima Perspectives on Civil Justice and ADR: Japan and the USA (Chuo Univ Press, Tokyo, 1990).

6 T Tanase "The Management of Disputes: Automobile Accident Compensation in Japan" (1990) 24 Law \& Soc'y Rev 651; Daniel Foote "Resolution of Traffic Accident Disputes and Judicial Activism in Japan" (1995) 25 Law in Japan 19. As a result of some tentative interview research in 1985, personally I have my doubts as to the effectiveness of the increasingly bureaucratic way in which this type of dispute is resolved in Japan. See also Y Wada "Koshoteki Chitsujo to Fuhokoi Seido [Negotiated Order and the Tort System]" in T Tanase (ed) Gendai no Fuhokoi-ho [Contemporary Tort Law] (Yuhikaku, Tokyo, 1993). See also Part V below. 
community revival. ${ }^{7}$ Dispute resolution becomes focused on restoring cooperative human relations and revitalisation of the community, rather than legal considerations.

However, there are doubts as to the practicality of this approach, in fragmented contemporary urban communities where rights consciousness has also increased. In fact, this type of ADR has suffered from a perennial shortage of cases and difficulties in attracting funds. As it comes to rely on funding support and referral of cases from the courts and the police, it becomes more difficult to retain its original ideals, and there are fewer and fewer functional differences with II.A(2)-type ADR. Here too, we should note that the litigation process is seen as a formal dispute resolution process diametrically opposed to flexible, or sometimes anti-legal, ADR. Although there is a difference in seeing litigation in a negative rather than a positive light, the perceived dichotomy between formal and informal process is a point in common with the abovementioned Pro-Litigation category.

\section{The Pro-litigation Anti-ADR Position: Second Class Justice}

Negative overall perceptions of ADR can similarly entail seeing the traditional litigation process in either a positive and a negative light. The former view argues that the price ADR pays for quick and simplified resolution of disputes is less procedural fairness through due process, and the loss of the opportunity for substantive review by judges, and thus that ultimately ADR merely offers cheap but second-class justice which will reflect power imbalances between the parties. The negative perception of ADR is further developed by arguments that court-assisted settlements come at the expense of the important role of litigation in setting clear standards by means of publicised and objective judgments, and that they can permit excessive intervention by managerial judges. Nonetheless, this ProLitigation Anti-ADR position shows great faith in the functionality and legitimacy of the traditional litigation process on which it is premised.

\section{$D$ The Anti-Litigation Anti-ADR Position}

By contrast, a negative perception of ADR can follow from a consistently sceptical view of the traditional litigation process. This view argues that the existing legal dispute resolution system does not add to fairness in society; it even adds to unfairness. ADR is said to work to hide this defect in the judicial system from critical gaze, and ultimately to act as a

7 Intensive critical research into this Community Board can be found in S E Merry and N Milner (eds) The Possibility of Popular Justice: A Case Study of Community Mediation in the United States (Univ of Michigan Press, 1993). Although this is perhaps contrary to common perceptions among foreign observers of Japanese dispute resolution, this type of completely extra-legal resolution is in fact rare in Japan. An example might be dispute resolution through the leaders of rural communities; but it is almost impossible to find them exercising this sort of function in Japan, compared to others like organising community activities. Cf J O Haley Authority without Power: Law and the Japanese Paradox (Oxford Univ Press, New York, 1991) esp 58-66, 175-181. 
means for the state to expand its control into all areas of society. ${ }^{8}$ In particular, this view criticises the expansion of II.A(2)-type ADR linked to the traditional judicial system, premised on the provision of court-like dispute resolution, on the basis that it encourages the expansion of simplified legal control by legal professionals.

This concludes a brief review of the various basic perceptions of ADR, according to whether they perceive litigation and ADR itself in a positive or a negative light. Due to limitations of space, this article cannot fully explore the various positions. Nor will the merits of each be discussed, as such. Instead, from a legal sociologist's viewpoint, this article will now raise a number of issues that have been lacking in the debate about these various positions, aiming to deepen the level of debate on ADR.

\section{UNEXPLORED ISSUES IN THE ADR DEBATE}

From a legal sociologist's viewpoint, there are a number of issues in the ADR debate which are generally taken as unproblematic or simply not even singled out. ${ }^{9}$ A sociological perspective seems essential to evaluate ADR in detail and to extract some hints for the reconstruction of our dispute resolution system. The issues can be summarised under four headings.

\section{A The Subjectivity and Dynamism of "Disputes"}

The most fundamental epistemological error in the ADR debate is to take a "dispute" as a given "social fact" centred on an expressed difference regarding rights and obligations or specific property. In this way, a dispute is separated from the perception of the disputing parties themselves, emasculated through being "objectively" defined by legal professionals or legal academics as a "focused standoff relating to specific values and interests". Further, by taking a dispute as something fixed and objectively determined, it is set up as the object for the dispute resolution institution to "resolve". In other words, the dispute resolution institution becomes the subject which resolves the object, the dispute.

However, from a sociological perspective, a dispute is not a static "event" subsumed into a fixed standoff. A dispute is usually part of a dynamic process, whereby the parties' own subjective constructions of reality evolve through negotiations between themselves and in sessions involving the institutions in question. The parties' perception of a dispute is

8 R Abel "The Contradictions of Informal Justice," in R Abel (ed) The Politics of Informal Justice, vol 1, 267 (Academic Press, New York, 1982).

9 Cf the concept of "litigotiation", ably explored by M Galanter, in L Lipson and S Wheeler (eds) Law and Social Sciences, New York, 1986). However, in this pathbreaking work, Galanter is unable to take all the issues to the conclusions reached in this paper. 
polycentric, ${ }^{10}$ fluctuating in the midst of non-legal issues such as human relationships with the other party, relationships to social context, emotional reactions, and so on. Such a subjective and dynamic view of a dispute means that only the parties themselves can "resolve" a dispute. Dispute resolution institutions can only assist in dispute resolution by the parties through providing some procedural regulation: what might be called an "institution-level resolution". In considering dispute resolution processes, we must not forget that the parties themselves typically face disputes, even after leaving the session(s) at the dispute resolution institution or after "the final decision" of the institution - whether in the form of a judgment or an agreement - has been reached.

\section{B The Temporality of Dispute "Resolution" and the Function of the Process Itself}

Almost all debate on ADR focuses on the dispute "resolution" as an output, whose performance is to be evaluated. To determine the success of the dispute resolution institution, one then asks for instance whether the "content" of the resolution is inferior to that obtainable through formal litigation, ${ }^{11}$ or else whether it indicates that the institution is achieving a function distinct from that of litigation, namely in restoring relationships between the parties. Even when the procedural channels are examined, they are viewed from the perspective of the correctness of the resolution output. Underlying this is the ephemeral axiom that the dispute ends - or should end - upon a final output in the sense of "the correct decision" or "an effective agreement", obtained through the dispute resolution institution.

However, as just mentioned, for the parties the dispute continues to develop even after the resolution proposed by the dispute resolution institution. Instead, the latter's resolution usually becomes the starting point for further negotiated adjustment of interests and exchange of benefits between the parties. Alternatively, the exchange during the process leading up to the "resolution" may have greater significance in terms of social result than the ultimate resolution. The individual exchanges at the dispute resolution institution sessions have considerable immediate influence on the relationship between the parties and the perception of the issues outside the institution, and move the dispute along in a social sense. Thus, at the social level, the dispute resolution institution's "final resolution" itself, while

10 Cf L Fuller "The Forms and Limits of Adjudication" (1978) 92 Harv L Rev 353. Fuller's exploration of the various types of dispute resolution mechanisms underpinned Sander's taxonomy, which has recently been criticised as the "new formalism": eg A Sarat "The 'New Formalism' in Disputing and Dispute Processing" (1988) 21 Law \& Soc'y Rev 695, and J P Esser "Evaluations of Dispute Processing: We Do Not Know What We Think and We Do Not Think What We Know" (1989) 66 Denv U L Rev 499. My view is that many, if not all disputes are or become polycentric.

11 See eg, in comparing out-of-court settlements in traffic accident disputes in Japan, M Ramseyer and M Nakazato "The Rational Litigant: Settlement Amounts and Verdict Rates in Japan" [1989] J Leg Stud 262. Cf the broader questions raised by T Tanase (1990) above $\mathrm{n} 6$. 
an important factor, is merely a milestone in a much longer process. If so, whether we are talking of formal litigation or of ADR, it is important to pay more attention to the social functions of the procedures played by the very process of reaching the resolution of the dispute, rather than seeing that resolution in absolute terms. This perspective has been noticeably missing in the ADR debate to date. ${ }^{12}$

\section{Limits to Typologies of Cases}

Another problem in many of the positions taken on ADR is the often tacit premise that it is possible to clearly distinguish between cases suitable for formal or informal procedures. Standards for this categorisation include factors like the difficulty of the legal issues involved, the social impact of the issues, the amount at stake, the continuity of the relationships, and so on. Certainly, in general terms, one should be able to establish some such categorisation. However that categorisation will always risk being based on a oneway view of disputes, from the viewpoint of the legal system. From a sociological viewpoint, for the parties themselves all disputes include factors making up social relationships between the parties and others involved. Factors like legal complexity and the amount at stake are only one side of the equation. Often, the former, extra-legal aspects of the relationship are more important even in legally complex disputes. On the other hand, careful consideration of procedures can become necessary even where the dispute is legally quite simple and involves a small sum. Thus, even if a broad categorisation can be made, both promotion of informal negotiation and the protection of formal procedures must be included in the process of resolving cases whatever category they are first separated into. It may be that almost all disputes fall into a category where aspects of both formality and informality are nonetheless required for appropriate resolution. A perspective capable of coping with this sort of dynamic change has also been weak in the ADR debate. ${ }^{13}$

\section{$D$ Limits to Typologies of Procedures}

A final problem in almost all ADR debate is the view based on categorisation of formal and informal procedures as forming two extremes on the same spectrum. Certainly, categorisation is sometimes refined by factors such as the extent of procedural formality, the extent of compulsoriness, and whether outputs are based on imposed decisions or on agreements. However, the basic dichotomy remains.

12 But see eg Harunori Inoue Minji Tetsuzukiron [The Theory of Civil Procedure] (Yuhikaku, Tokyo, 1993) and Wada, above $n 3$.

13 Cf eg Esser (above $n$ 10), with the relative lack of attention paid to this in the Woolf Report on reform of civil procedure in the UK. In Japan, $\mathrm{H}$ Inoue "Saiban Tetsuzuki no Tegaruna Riyo no tame $n i$ [Towards a More Relaxed Use of Litigation Procedures]" in H Inoue (above $n$ 12), has argued that the parties should have the utmost flexibility in moving from informal to formal modes and vice versa. 
The particular problem here is that the image of the formal litigation process is built on an idealised version of the actual litigation process. Litigation is indeed a dispute resolution mechanism made up of detailed procedural rules. However, when these specific rules are applied to the resolution process for a particular case, the parties' original interpretations come into play in the midst of contextual aspects including a variety of extra-legal factors specific to the case. The recent "epistemological turn" demonstrates how it is impossible to conceive of application of universal and formal standards independent of the practices embedded in specific situations. ${ }^{14}$ Actual litigation can be perceived as formal procedural rules forming the backstage to the process of informal and dynamic interactions betweeen the parties, their lawyers, judges, and others. Informality is buried deeply within formality; formality is necessarily a part of informality. This view of informality and formality differs slightly from the conceptions used in the ADR debate so far; but is essential to bring out accurately the dynamism that is not captured by the usual dichotomy.

Similarly, turning to ADR premised on agreement reached by the parties, we can see that the mediator does not just promote or facilitate negotiations. Even without intending it, her utterances typically act to control the parties to some extent. ${ }^{15}$ The theory that ADR premised on agreement represents a process freed from being bound in any way by third parties risks overlooking the subtle power plays involved even in such ADR processes.

Thus, four issues insufficiently argued in the ADR debate so far emerge from a more detailed view of the dynamism of the dispute resolution process, informed by the perspective of legal sociology. By way of summary, two broad implications can now be drawn.

\section{IMPLICATIONS OF A DYNAMIC VIEW OF THE DISPUTE RESOLUTION PROCESS}

\section{A Reconceptualising the Formal Litigation Process}

The first implication - still tentative, and very generally argued in this article - is the possibility of a radical reconceptualisation of the formal litigation process itself. The perception of the polycentric nature of a dispute means that there should be flexible implementation of procedural rules to allow the development of debate between the parties

14 In the United States, the "turn" in the field of sociology of law can be traced back to the works of the Amherst Seminar: (1985) 9 Legal Studies Forum. See also S Silbey and A Sarat "Critical Tradition in Law and Society Research" (1987) 21 Law \& Soc'y Rev 165, D M Trubek and J P Esser "Critical Empiricism in American Legal Studies: Paradox, Program, or Pandora's Box?" (1990) 15 L \& Soc Inquiry 171 and Y Wada Hoshakaigaku no Kaitai to Saisei [Deconstruction of Sociology of Law] (Kobundo, Tokyo, 1996).

15 See C Harrington and SE Merry "Ideological Production: The Making of Community Mediation" (1988) 22 Law \& Soc'y Rev 709 and S E Merry " The Discourses of Mediation and the Power of Naming" (1990) 2 Yale J L \& Human 1. 
themselves from an extra-legal perspective, even in the formal litigation process. ${ }^{16}$ In this way, lawyers and judges will also suggest their own understandings of the relationship between legal resolution of disputes and the perception of extra-legal issues, and subject themselves to monitoring by the parties on that level as well. This change away from "procedure for resolution" of the dispute, and towards "procedure as procedure in itself", will also promote a more sensitive and responsive reaction to changes in the needs and perception of the parties as the formal procedure unfolds. In sum, this approach exposes the hidden informality of the formal litigation process, and extends the access and control of the parties themselves in that regard.

That does not diminish the significance of the formal dispute resolution process. Instead, it exposes legal professionals' unconstrained use of discretion in the form of informality, masked by the myth of an idealised formal dispute resolution process. Hence it aims to promote dispute resolution through the legal system which is truly meaningful for the parties. The fusion of informality and formality in this way means the functional joining of legal dispute resolution and dispute resolution seen in terms of the parties and of legal sociology, and promises subjective control by the parties over the management of disputes and the satisfaction that brings.

\section{$B$ Reconceptualising $A D R$}

The second implication relates to ADR itself. If we stress the process itself rather than the "resolution" of the dispute in the sense of an output of a dispute resolution institution, an important issue becomes how to provide some guidance and support for changes to the parties' perception of the dispute, rather than (say) achieving agreement. Of course, there is little difficulty with achieving agreement as a general objective; but becoming fixated with this makes it easier for the way to open to subtle control of the parties by mediators and others involved in the process. This can arise because of neglect of the subjective perception of the issues by the parties, or indeed perhaps the mobilisation of normative apparatus such as "community values", or resolution standards similar to those in litigation. All these can put considerable pressure on the parties.

In any event, in evaluating $\mathrm{ADR}$, the detail of the responsiveness of process implementation should be stressed rather than the performance of the "resolution" achieved.

16 For instance, an informal dispute resolution practice in Japan has become more and more evident over the last decade, namely flexible court session in which formal trial process and settlement process are merged (wakai ken benron). Although this can be utilised by parties to define and control their dispute from their own perspectives, there is also a risk that it works just as a means for a judge and lawyers to dispose of cases more quickly from their "expert" perspectives. The reality and its evaluation is complicated. See eg Kosho to Ho Kenkyukai (ed) Saiban nai Kosho no Ronri: Wakai ken Benron wo Kangaeru [Structure of Negotiation within the Litigation Process: Thoughts on Wakai ken Benron] (Shojihomu, Tokyo, 1993). 
We also need to better grasp the precise relationships between "compulsion" and "autonomous adjustment" in processes as they are actually played out, rather than focusing on an overly technical definition and approach to informality. For this, sociological research focused on the construction of meaning in everyday life, and on implementation and process rather than structure, becomes all the more essential.

The distinction between formal and informal procedures is still useful in depicting a wider, structural framework. However, the trend suggested by the four issues outlined and the two implications drawn in this paper suggests that the distinction between formality and informality may be crumbling in the face of specific dispute resolution processes as seen from a sociological perspective. Views will differ on how to analyse this further, and whether it is a useful development or not. But it seems that we must already be aware that both formality and informality are basic factors in appropriate resolution of disputes, of whatever nature.

\section{$V$ CONCLUDING OBSERVATIONS: ANALYSIS AND CRITIQUE OF THE TRAFFIC ACCIDENT DISPUTE RESOLUTION SYSTEM IN JAPAN}

This point can be developed with respect to traffic accident compensation disputes in Japan. In the 1960s the number of cars on the roads in Japan increased rapidly and courts were soon packed with traffic accident cases. To resolve this situation, Japanese courts, the Ministry of Justice, lawyers, and insurance companies tried to produce a predictable and effective compensation system. First, the Traffic Accident Compensation Act was enacted. Mandatory insurance was introduced, and no-fault responsibility was applied. Secondly, optional insurance became increasingly prevalent (now held by around $70 \%$ of drivers). Nowadays, the average payment for accidental death is about one million New Zealand dollars. An important point is that under this insurance regime, the insurance company's clerk will take charge of compensation negotiations, representing the customer, when an accident happens. This can be viewed as a sort of ADR. It is said that $96-97 \%$ of cases are disposed of under this system. In addition, the Bar Associations and the Insurance Industry Association have founded ADR institutions specializing in processing traffic accident cases. Thirdly, amounts and categories of compensation were standardised. In the Japanese system, compensation is divided into three categories: positive damages (ie out of pocket expenses, including medical expenses), negative damages (ie lost profits or income, including lost profits or income by death or after-effects), and damages for mental suffering. Each category has become more and more finely divided, with the amount of compensation decided then based on the class of after-effects or the number of days hospitalized, for example. ${ }^{17}$

17 See generally Tanase (1990) above $\mathrm{n} 6$. 
As the result of these changes, litigation in this field decreased dramatically. This scheme has two facets. On the one hand, monetary compensation for victims has undoubtedly been improved. Although the basic legal scheme in this field is still fault liability, the combination of the above mentioned elements of the system make it function as if it were a strict liability scheme. Almost all victims can obtain enough monetary compensation, through a fast and simple process. On the other hand, most victims interviewed by this author have serious complaints regarding way their dispute has been processed. In other words, institutional actors - including courts, lawyers, ADR institutions, and insurance companies - all define the traffic accident case in terms of the amount of compensation, and the other party disappears from the disputing process. Parties, defining their problems as matters involving human relations and in emotional terms, unsuccessfully try to make institutional actors listen to their perceptions of the problem. In the ordinary person's view, which does not seem peculiar to Japanese people, it is very rude to define this sort of problem solely in terms of money. ${ }^{18}$

Of course, monetary compensation is very important for victims; but their focus is often on relational considerations. Herein lies an important contradiction. Both ADR and litigation, especially in the context of traffic accident disputes, define the problem almost exclusively in terms of standardised compensation from the very beginning, and lack sufficient ways to help parties dissolve that contradiction. As a result, although victims obtain monetary compensation, they become critical of the legal system and fierce emotional conflict remains unresolved. It is essential to give parties the chance to express their own perceptions, including those as to extra-legal problems, and to control their own disputes for themselves.

In general, the Japanese system emphasizing monetary compensation for traffic accident victims still works very well. However, if the dispute resolution processes support parties in giving their own meanings to compensation money, it can work much better. Money can work as a neutral medium which can convey a variety of meanings. It can be perceived as a symbol of rudeness or as a symbol of consolation. The parties themselves, not the institutional actors, should give meaning to monetary compensation. For this, an appropriate combination of formality and informality is required.

18 From this perspective, a detailed empirical study deserves to be undertaken of the dispute resolution process involving accidents in New Zealand, under its accident compensation scheme. 
(1997) 27 VUWLR 